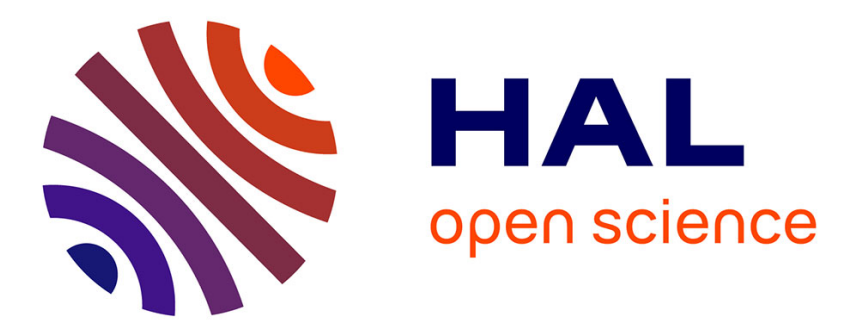

\title{
GRID IMPACT OF A WAVE FARM ON ITS LOCAL NETWORK: ANALYSIS OF VOLTAGE AND FLICKER LEVELS
}

Anne Blavette, Dara O’Sullivan, Ray Alcorn, Antony Lewis, Michael Egan

\section{- To cite this version:}

Anne Blavette, Dara O'Sullivan, Ray Alcorn, Antony Lewis, Michael Egan. GRID IMPACT OF A WAVE FARM ON ITS LOCAL NETWORK: ANALYSIS OF VOLTAGE AND FLICKER LEVELS. 31st International Conference on Ocean, Offshore and Arctic Engineering, Jul 2012, Rio de Janeiro, Brazil. pp.435-443, 10.1115/OMAE2012-83616 . hal-01266001

\section{HAL Id: hal-01266001 https://hal.science/hal-01266001}

Submitted on 14 May 2018

HAL is a multi-disciplinary open access archive for the deposit and dissemination of scientific research documents, whether they are published or not. The documents may come from teaching and research institutions in France or abroad, or from public or private research centers.
L'archive ouverte pluridisciplinaire HAL, est destinée au dépôt et à la diffusion de documents scientifiques de niveau recherche, publiés ou non, émanant des établissements d'enseignement et de recherche français ou étrangers, des laboratoires publics ou privés. 


\section{GRID IMPACT OF A WAVE FARM ON ITS LOCAL NETWORK: ANALYSIS OF VOLTAGE AND FLICKER LEVELS}

\author{
Anne Blavette \\ HMRC, University College Cork \\ Cork, Ireland
}

\author{
Dara L. O'Sullivan \\ HMRC, University College Cork \\ Cork, Ireland
}

\author{
Ray Alcorn \\ HMRC, University College Cork \\ Cork, Ireland
}

\author{
Antony W. Lewis \\ HMRC, University College Cork \\ Cork, Ireland
}

\author{
Michael. G. Egan \\ Electrical Engineering Dpt, \\ University College Cork \\ Cork, Ireland
}

\section{ABSTRACT}

Most oscillating wave energy converters without significant amounts of energy storage capacity generate significant electrical power fluctuations in the range of seconds. Because of these fluctuations, a wave farm may have a negative impact on the power quality of the local grid to which it is connected. Hence, the impact of these devices on both distribution and transmission networks needs to be well understood, before large scale wave farms can be allowed to connect to the grid.

This paper details a case study on the impact of a wave farm on the distribution grid around the national wave test site of Ireland. The electrical power output of the oscillating water column (OWC) wave energy converters was derived from experimental time series produced in the context of the FP7 project "CORES". The results presented in this paper consider voltage fluctuation levels and flicker levels for a typical time series. Simulations were performed using DIgSILENT simulation tool "PowerFactory".

\section{INTRODUCTION}

A site off the west coast of County Mayo, Belmullet was selected in 2009 by the Irish government to become the national wave energy test site of the Republic of Ireland. The test site is planned up to a maximum generating capacity of $20 \mathrm{MW}$, (although initially it will be utilised as a 5MW test site). The geographical configuration of the wave farm and the electrical components ratings are modelled in this study according to the design planned by the test site operator, ESBI.

The study intends to analyse the electrical impact of the wave farm on the Belmullet local grid. This is done by analysing the voltage and flicker levels at the grid connection point between the wave farm and the rest of the national grid, also referred to as PCC (Point of Common Coupling).

Each wave energy converter is modelled by means of a DIgSILENT built-in "Static Generator" model, representing a generator connected to the grid via fully-rated back-to-back PWM converters. The electrical power output of each generator was modelled using an experimental power time series from the
CORES project. This time series was shifted by certain time delays in order to represent the effect of device aggregation on the wave farm power output. This method is explained more in detail in section "Aggregation modelling". It was not intended to study the internal parameters of the generators, as the focus of the study was on the grid itself.

\section{1- Modelling of the National wave test site of Ireland}

The wave farm consists of two clusters (each including up to 11 generators). Each generator represents an actual full-scale device rated at $882 \mathrm{~kW}$. Each generator is modelled by means of a DIgSILENT built-in "Static Generator" model. This model represents a generator connected to the electrical network through fully-rated PWM converters. Each generator is connected to an offshore $0.4 \mathrm{kV} / 10 \mathrm{kV}$ transformer.

The grid model used in the current study is shown in Figure 1.

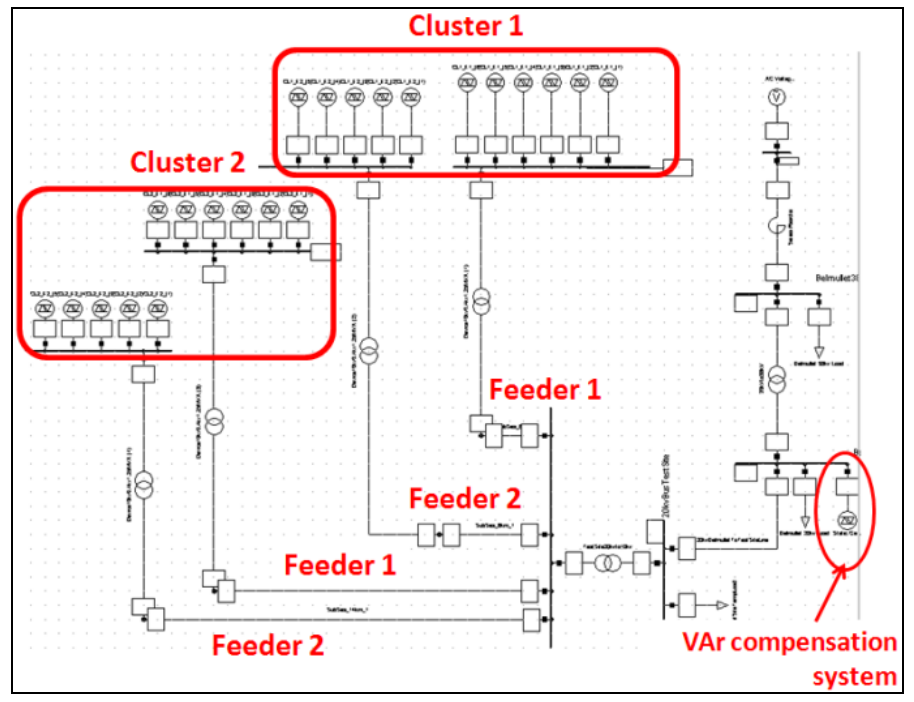

Figure 1 Grid model (DIgSILENT)

Two clusters are connected to the shore by two ac subsea cables each, one being $6.5 \mathrm{~km}$ long, the other being $16 \mathrm{~km}$ long. The cluster located at a $6.5 \mathrm{~km}$ distance from the shore will be referred to as Cluster 1, whereas the other cluster $(16 \mathrm{~km}$ from 
the shore) will be referred to as Cluster 2. Each cluster consists of two radial feeders (Feeder 1 and Feeder 2) to which wave energy converters are connected.

An onshore substation located in the area of Belderra strand steps the voltage up to $20 \mathrm{kV}$. Then, the wave farm is connected to the rest of the national network of Ireland by a 5-km long, $20 \mathrm{kV}$ overhead line, although the current design of the project includes a $10 \mathrm{kV}$ overhead line. However, this type of $10 \mathrm{kV}$ lines are being progressively replaced around Ireland by $20 \mathrm{kV}$ lines. Besides, as the case study examines the impact of a farm of power capacity ranging from $5 \mathrm{MW}$ to $20 \mathrm{MW}$, it was deemed reasonable to consider a $20 \mathrm{kV}$ line. The rest of the national network has been modelled by a $20 \mathrm{kV} / 38 \mathrm{kV}$ transformer connected to a fixed voltage source in series with a reactor. The impedance of this reactor represents the shortcircuit impedance at this node, which was estimated to be equal to $18.8 \Omega$ from the EirGrid Transmission Forecast Statement [1].

Studies have been performed for a farm power capacity ranging from $5.3 \mathrm{MW}$ (6 generators) to $19.4 \mathrm{MW}$ (22 generators).

\section{2- CORES project}

CORES stands for "Components for Ocean Renewable Energy Systems". It is an FP7 European collaborative research project focusing on the development of new concepts and components for power-take-off, control, moorings, risers, data acquisition and instrumentation for floating wave devices [2]. The project itself was based on a floating OWC-type system. The project began in April 2008 and ended in December 2011. The quarter-scale OWC prototype used in the project was deployed offshore from March to May 2011.

The device was connected to a small on-board island grid independent from the national electrical network. Figure 2 shows the on-board operating and monitoring system.

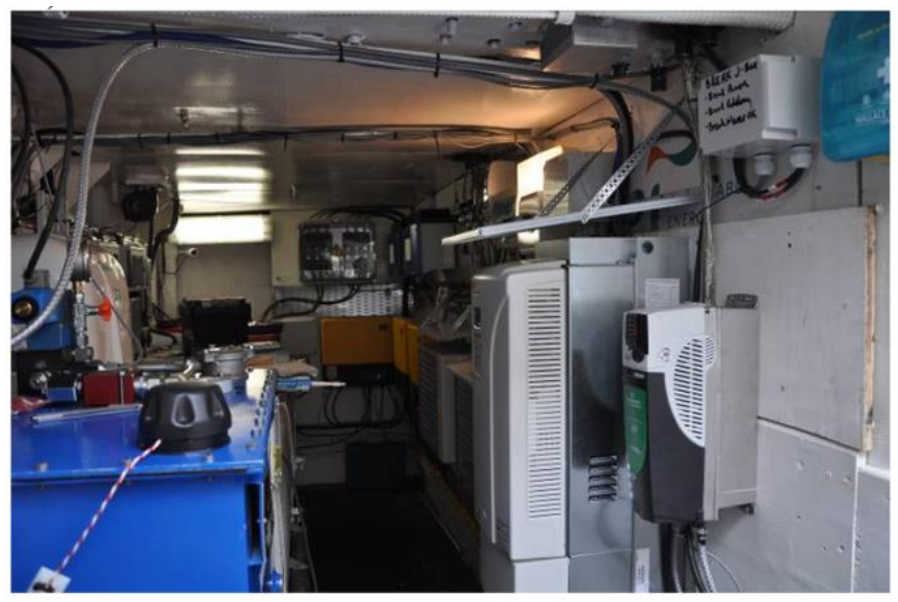

Figure 2 On-board operating and monitoring system

The on-board grid was maintained by three dc inverters and generated power was used to charge the on-board battery system, or dumped in resistive load banks. A variablefrequency converter and a diesel generator were also included. Figure 3 shows the OWC deployed offshore.

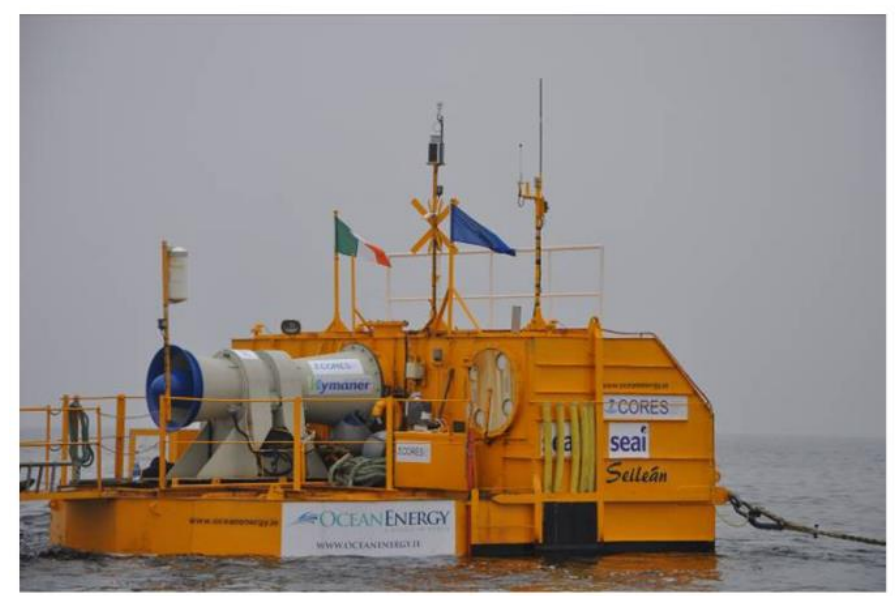

Figure 3 OWC deployed in Galway Bay

The project has allowed the ocean energy research community to gain significant practical experience in the deployment, operation, maintenance of offshore ocean energy converters. It has also generated a considerable amount of time series data on a number of parameters, including electrical parameters at a resolution of $0.1 \mathrm{~s}$. Contrary to most available data which is averaged over a sea-state, a season or even a year, the CORES electrical power time series data can be scaled and used directly for grid impact studies.

The time series used in this study was recorded on $31^{\text {st }}$ March 2011 and the simulation lasts 27 min $45 \mathrm{~s}$ (with respect to full-scale time). During this period, the generator was operated in constant speed control mode: in this control mode, unlike in variable speed operation, inertial energy storage by means of speed control is not available. As a result, mechanical power peaks are converted directly into electrical power peaks. Hence, this control mode represents a worst case with respect to power quality impact. Figure 4 shows the electrical power time series during the selected sequence, scaled to a full scale device power level:

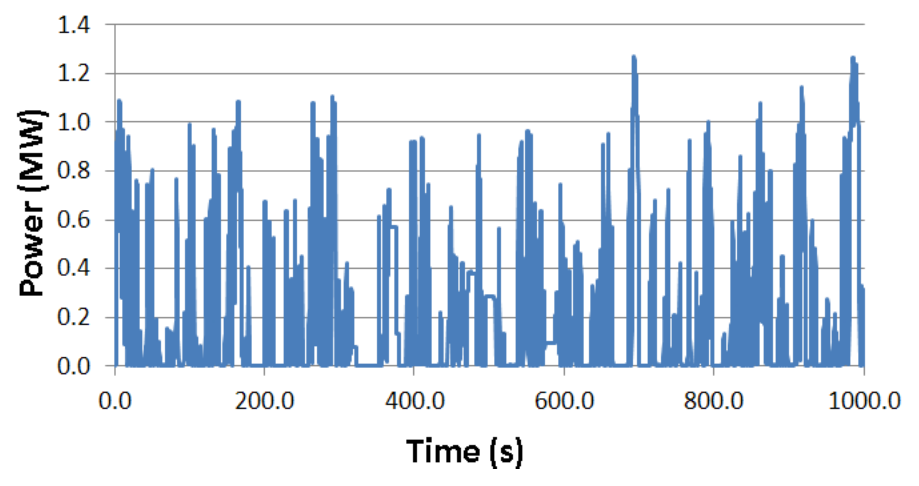

Figure 4 Power output of a generator 


\section{3- Simulation scenarios}

Several simulation scenarios have been designed in order to analyse different aspects of the wave farm grid impact. In particular, studies have been performed to analyse the influence of an increasing farm power capacity on minimum and maximum instantaneous voltage levels, as well as on maximum flicker severity level. Hence, 4 power capacity values have been defined, namely 5.3 MW, 9.7 MW, 15.0 MW and 19.4 MW and simulations have been performed for each. Farm power capacity has been varied by switching a defined number of generators on or off, as detailed in Table 1.

\begin{tabular}{|c|c|c|c|c|}
\hline Capacity (MW) & $\mathbf{5 . 3}$ & $\mathbf{9 . 7}$ & $\mathbf{1 5 . 0}$ & $\mathbf{1 9 . 4}$ \\
\hline Number of generators (total) & 6 & 11 & 17 & 22 \\
\hline $\begin{array}{c}\text { Number of generators } \\
\text { (cluster 6 km) }\end{array}$ & $\mathbf{3}$ & $\mathbf{6}$ & $\mathbf{9}$ & $\mathbf{1 1}$ \\
\hline Feeder 1 & 2 & 3 & 5 & 6 \\
\hline Feeder 2 & 1 & 3 & 4 & 5 \\
\hline $\begin{array}{c}\text { Number of generators } \\
\text { (cluster 16 km) }\end{array}$ & $\mathbf{3}$ & $\mathbf{5}$ & $\mathbf{8}$ & $\mathbf{1 1}$ \\
\hline Feeder1 & 2 & 3 & 4 & 6 \\
\hline Feeder 2 & 1 & 2 & 4 & 5 \\
\hline
\end{tabular}

Table 1 Number of generators with respect to the farm power capacity

Device aggregation is generally expected to have a beneficial impact on the farm power output quality. This is based on the assumption that individual wave reach wave energy converters at different times, hence introducing some time delays between the individual generator power outputs. In this study, device aggregation was analysed with respect to wave direction using two extreme cases from a power quality perspective (Cases A and B), as shown by Figure 5 .

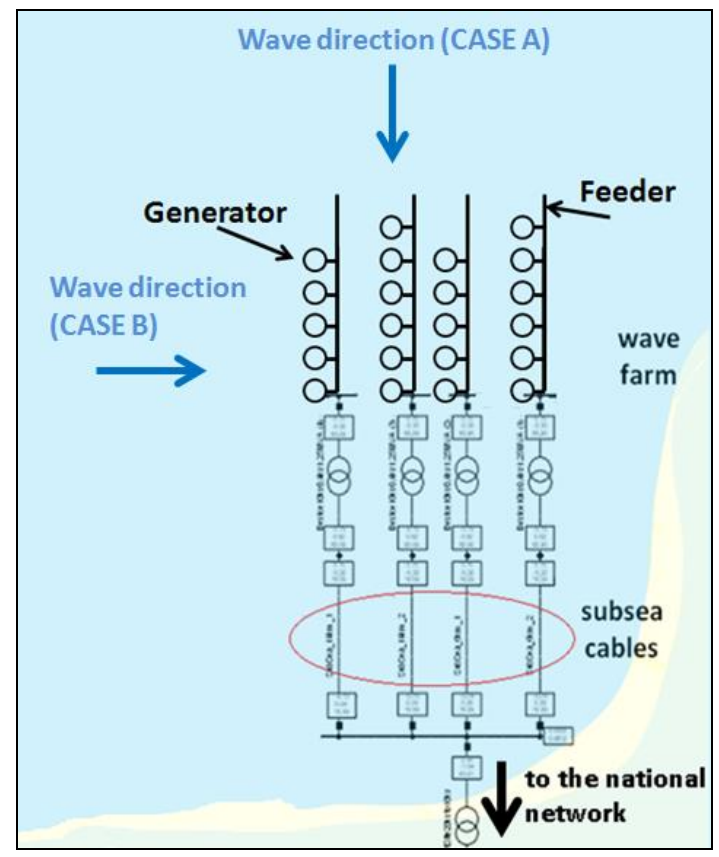

Figure 5 Cases involving different wave directions

In the worst case (Case B), wave converters connected to the same cable generate the same power output as shown in Figure 6. This scenario represents mono-directional waves propagating perpendicularly to the feeders. Power transported by a particular subsea cable is hence not smoothed as all the generators output the same power peak at the same time. As a result, power variations are expected to be higher in amplitude, and so would be voltage variations. However, two generators connected to two different feeders show a power output shifted by a defined time delay (see section "Aggregation modelling").

Hence, the expected beneficial impact of aggregation, as represented in Case B, exists between feeders, but not along a feeder. The other extreme case, which represents a best case, is referred to as Case A. In this case, all generators connected to the same feeder show a power output shifted by a different time delay each. Generators belonging to different feeder can show similar power output though. 


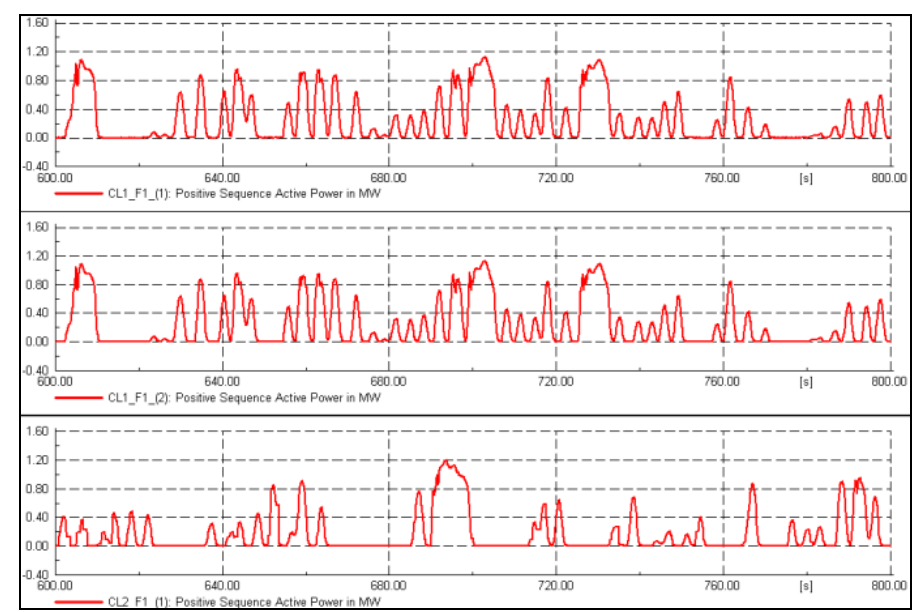

Figure 6 Case B: Power output of generators located on Cluster 1, Feeder 1 (top and middle) and on Cluster 1, Feeder 2 (bottom)

As shown in Figure 7 below, the power output of both generators located on Feeder1 are different, whereas the power output of 2 generators located on different feeders is similar. The beneficial impact from device aggregation is hence maximal here.

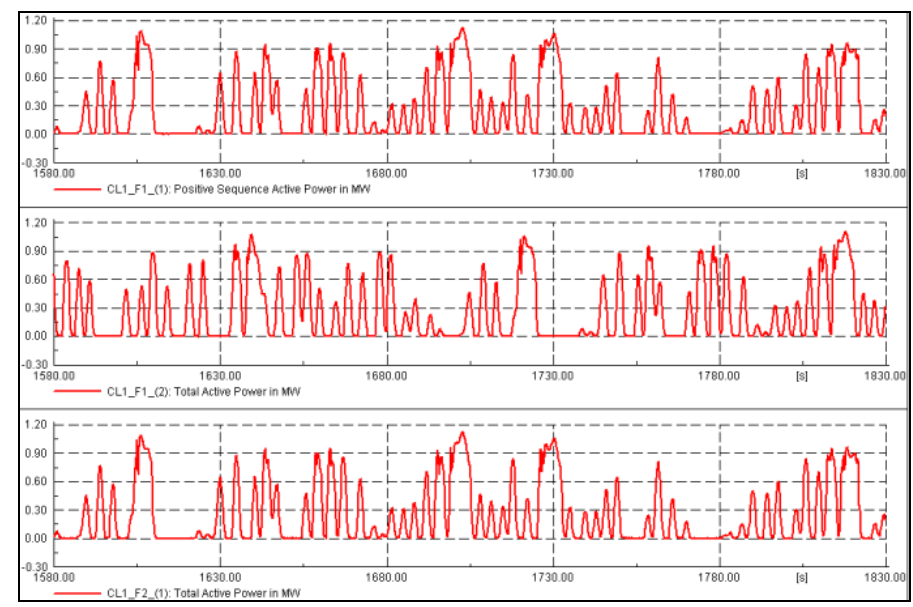

Figure 7 Case A: Power output of generators located on Cluster 1, Feeder 1 (top and middle) and on Cluster 1, Feeder 2 (bottom)

As explained more in detail in the next section, randomly generated time delays have been used to model device aggregation impact on the wave farm power output. In order to study different cases of aggregation, up to 11 time delay sets have been generated. Table 2 sums up the different simulation scenarios that have been performed for this case study. For time delay set 11, Cases A and B are equivalent.

\begin{tabular}{|c|c|c|c|c|}
\hline & \multicolumn{4}{|c|}{ Power capacity (MW) } \\
\hline Time delay sets & 5.3 & 9.7 & 15.0 & 19.4 \\
\hline Set 1 & \multirow{11}{*}{\multicolumn{4}{|c|}{ Case A + Case B }} \\
\hline Set 2 & & & & \\
\hline Set 3 & & & & \\
\hline Set 4 & & & & \\
\hline Set 5 & & & & \\
\hline Set 6 & & & & \\
\hline Set 7 & & & & \\
\hline Set 8 & & & & \\
\hline Set 9 & & & & \\
\hline Set 10 & & & & \\
\hline Set 11 (reference) & & & & \\
\hline
\end{tabular}

Table 2 Simulation scenarios

\section{4- Aggregation modelling}

The instantaneous electrical power output of a wave farm including a significant number of devices cannot be modelled by multiplying the electrical power output of one single device by the number of devices included in the farm, as it is usually done for wind farms. However, the effect of device aggregation within a wave farm can be modelled by shifting the electrical power output of one single device by randomly defined time delay to create the expected power output of another generator. This method does not intend to represent precisely the wave conditions at each of the generators within a farm, but rather at representing typical time shift between the generator power outputs. An exact analysis of the wave condition between the generators is a complex 3D hydrodynamic problem, which is beyond the scope of this study.

For this study, up to 11 time delay sets have been used. Among these time delay sets, 10 include time delay which have been randomly generated between $100 \mathrm{~s}$ and $250 \mathrm{~s}$. The time range was chosen based on the following assumptions: 1) devices spaced by $1000 \mathrm{~m}$ from each other, 2) interesting waves, from an electricity generation perspective, lay in the range of $5 \mathrm{~s}$ to $12 \mathrm{~s}$. Finally, the time delay range has been determined using the formula for wave group speed in deep water [3]. A reference case (time delay set 11) in which time delay is equal to zero between the generators belonging to the same cluster was also studied.

As the two clusters are $10 \mathrm{~km}$ away from each other, it is also necessary to add another time delay to represent the impact of this distance on the wave farm power output. This was achieved by shifting the electrical power output between the generators belonging to Cluster $1(6.5 \mathrm{~km})$ and these belonging to Cluster $2(16 \mathrm{~km})$ by an additional time delay of $1000 \mathrm{~s}$, using the same assumptions outlined previously. 


\section{5-Grid Code requirements}

In order for power plant managers to be allowed gridconnection, their power plant must comply with a number of requirements issued by grid operators called Grid Code requirements. These Grid Code requirements ensure that power systems are operated in a safe and reliable way.

So far, as the impact of ocean farms on the network in general is relatively unknown, no specific grid code requirement addressing the potential grid impact issues generated by wave energy converters has been issued. However, some grid code requirements for wind turbines have proven to be relatively challenging for the turbine manufacturers, as implying sometimes a partial re-design of their device. Hence, case studies such as the one proposed in this paper not only allow the grid operators to get a better understanding of the grid impact of wave farm, but it should also benefit device developers by increasing their awareness of potential grid impact issues.

In many countries, grid code requirements for wind farms have recently been appended to the main grid code, usually intended for synchronous generators directly connected to the grid. These requirements are usually called Wind Grid Code. Considering the similar features between wind and wave farms, in particular regarding power output variability, wind grid codes have been considered partially applicable for the wave farm considered in this study. The Grid Code taken into account in the current study is the Irish Grid Code [4].

Three main requirements regarding power quality are applicable to the considered wave farm: power factor limits, voltage limits and flicker level.

Considering the farm connection to a $20 \mathrm{kV}$ bus, power factor for each generator must be kept between 0.92 and 0.95 lagging at the PCC (lagging being referred here as reactive power absorption). This requirement was issued having wind farms connected to medium voltage distribution network in mind. Keeping a lagging power factor enables mitigation of the expected voltage rise due to direction reversal of the active power flow in this type of network.

However, applying a unity power factor at each of the wave energy converters is considered a reasonable option for minimising power losses in the cables, the $10 \mathrm{kV} / 20 \mathrm{kV}$ transformer and the overhead line. This option has been adopted for the case study. Besides, subsea cables generate reactive power which must be absorbed in order to keep the power factor lagging.

Hence, in order to comply with the power factor requirement, a VAr compensation system was implemented at the PCC. Power factor at the PCC was kept fixed at 0.93 lagging during the simulation.

Upper voltage limits for any node on the grid whose nominal voltage is $20 \mathrm{kV}$ is equal to $22.1 \mathrm{kV}$ (i.e. $1.1 \mathrm{pu}$ ). The lower limit, on the contrary, is not explicitly defined by the Grid Code which describes it as being "variable according to operation conditions". A typical range of $\pm 10 \%$ seems reasonable; hence an arbitrarily-defined lower voltage limit of $0.90 \mathrm{pu}$ was defined for the current study.

Flicker level, which will be explained in detail in the following section, must also be kept under a defined limit. The Irish Grid Code requires the short-term flicker level to be kept under 0.35 .

It must be noticed that for the considered grid connection configuration (PCC nominal voltage equal to $20 \mathrm{kV}$ ), no voltage regulation is required from the farm.

\section{FLICKER}

\section{1-Flicker}

Flicker is a phenomenon caused by voltage variations on a light bulb, which results in a varying light intensity. This phenomenon, although not particularly harmful to the electrical network, represents a visual disturbance to the electricity customers.

Hence, flicker instantaneous perceptibility and flicker statistical disturbance (referred to as flicker severity) have been extensively studied and their computation from voltage time series has been strictly defined in standard IEC 61000-4-15. Flicker limits in the Grid Code concerns flicker severity, which is a statistical index of the instantaneous visual disturbance over a given period. Grid operators, by limiting the voltage variations a power plant is allowed to emit, ensure visual disturbance remains negligible to the customer

As voltage variations can be induced by variable power output generators, this issue is of particular interest in wave energy grid integration research. However, although this topic has been widely covered in the field of wind energy, literature on this issue is still relatively limited in the field of wave energy. Besides, the wave farm aggregation effect is usually not taken into account in the studies. [5-6]

The interesting range of wave frequency from an electricity generation perspective is typically in the range of few tenths of Herz. As a wave converter generally produces electricity twice per wave cycle, the frequency of power output fluctuations and induced voltage amplitude variations is then multiplied by two. Then, as light intensity variation frequency is the double of voltage variation frequency, components presenting twice the frequency of the voltage amplitude variations appear. Hence, from interesting wave periods ranging between $5 \mathrm{~s}$ to $12 \mathrm{~s}$, the frequency of the light intensity variations generated by a single wave energy converter would range from $0.3 \mathrm{~Hz}$ to $0.8 \mathrm{~Hz}$.

Although flicker perceptibility in this frequency range is relatively low, as shown in Figure 8, flicker in the field of wave electricity generation is a complex issue which presents some aspects still to be investigated more in detail. First, the energy from a single propagating wave may be harnessed by several wave energy converters located at different places in a farm. Hence, the frequency of the resulting light intensity variations would increase with the number of wave devices in the farm, consequently making flicker caused by these variations become more perceptible to the electricity customers. 
Besides, aggregating wave energy converters in a farm may not only increase the frequency of light intensity variations but also their magnitude. As power peaks may be generated simultaneously by several wave energy converters, the amplitude of the resulting power peaks in the farm power profile may actually become significant in term of impact on flicker level. These aspects are studied in the paper.

In order to compute flicker severity levels from power system simulations, a numerical flickermeter has been created based on an existing design [6]. A flickermeter, as defined in IEC standard 61000-4-15, is constituted of 5 blocks. Blocks 1 to 4 perform the calculation of the instantaneous flicker level (i.e. flicker perceptibility). Then, from block 4 output, block 5 computes the flicker severity level.

Flicker severity level can be evaluated on a short-term (10 min) and on a long-term ( $2 \mathrm{~h}$ ) basis. These respective levels are called $\mathrm{P}_{\mathrm{ST}}$ and $\mathrm{P}_{\mathrm{LT}}$. In this study, the time series duration (27 min $45 \mathrm{~s}$ ) allowed computation of $\mathrm{P}_{\mathrm{ST}}$ only. However, as $\mathrm{P}_{\mathrm{ST}}$ must be calculated over $10 \mathrm{~min}, 2$ computations of $\mathrm{P}_{\mathrm{ST}}$ were performed in each case. The maximum value of $\mathrm{P}_{\mathrm{ST}}$ in each case has been retained for the analyses.

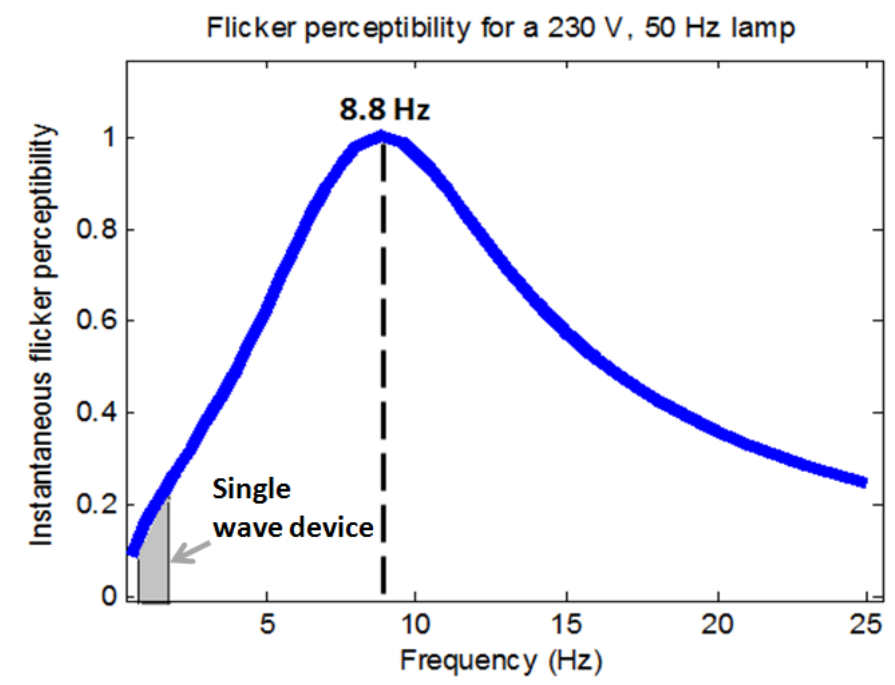

Figure 8 Instantaneous flicker perceptibility curve for a single wave energy converter

\section{RESULTS}

\section{1-Voltage limits}

No over-voltage is observed as voltage remains under 0.982 pu for both Cases A and B and for all time delay sets, including reference set 11 , which constitutes a worst case scenario.

Under-voltage is more of concern. In the worst case scenario (time delay set 11), voltage goes down to $0.906 \mathrm{pu}$, as shown in Figure 9, which is close to the lower limit of $0.90 \mathrm{pu}$.
However, this shows that even under worst case conditions, the wave farm is grid compliant with respect to voltage limits.

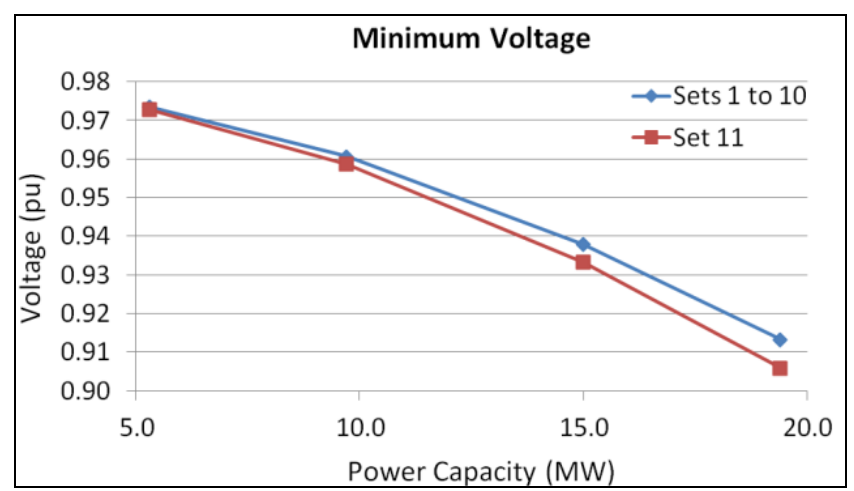

Figure 9 Minimum voltage (Cases $A$ and B)

For simulations including time delay sets 1 to 10 , minimal voltage goes down to $0.91 \mathrm{pu}$ for Case B (Figure 11) and to 0.94 pu for Case A (Figure 10), both for 20 MW. Hence, all voltages in Case A are maintained within $-6 \%$ of the nominal value. This demonstrates that having less in-phase generators is beneficial for maintaining the voltage at the PCC around its nominal value.

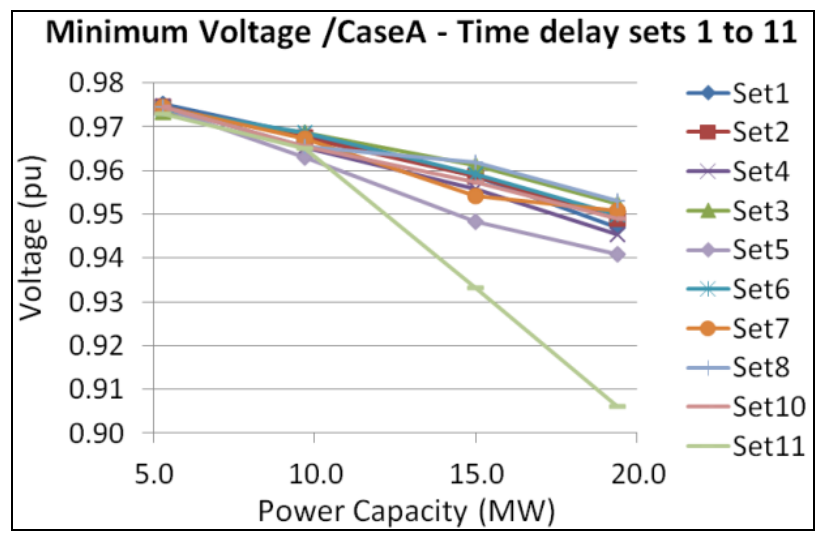

Figure 10 Minimum voltage versus power capacity (Case A)

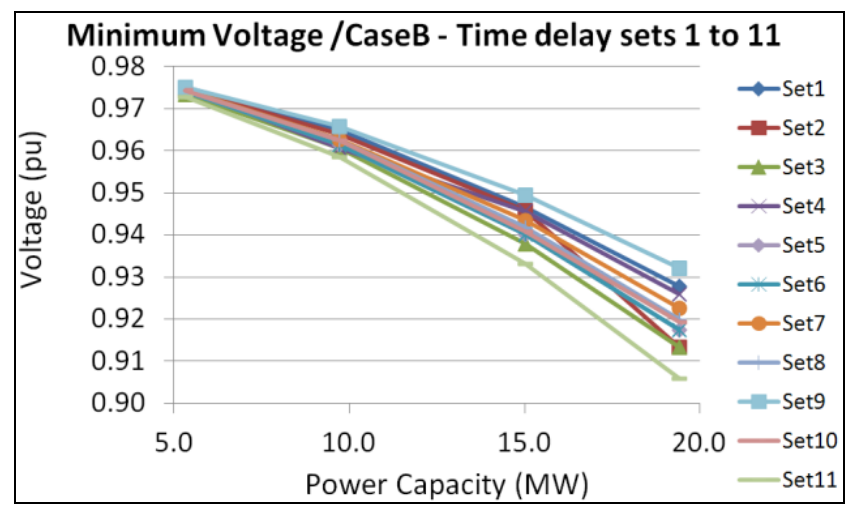

Figure 11 Minimum voltage versus power capacity (Case B) 
Wave direction is also shown to play an important role on PCC voltage impact: the difference in terms of minimum voltage between Case A and Case B is up to $0.03 \mathrm{pu}$ for the $20 \mathrm{MW}$ farm, as shown in Figure 12, which is significant with respect to the under-voltage allowed range of $-0.10 \mathrm{pu}$.

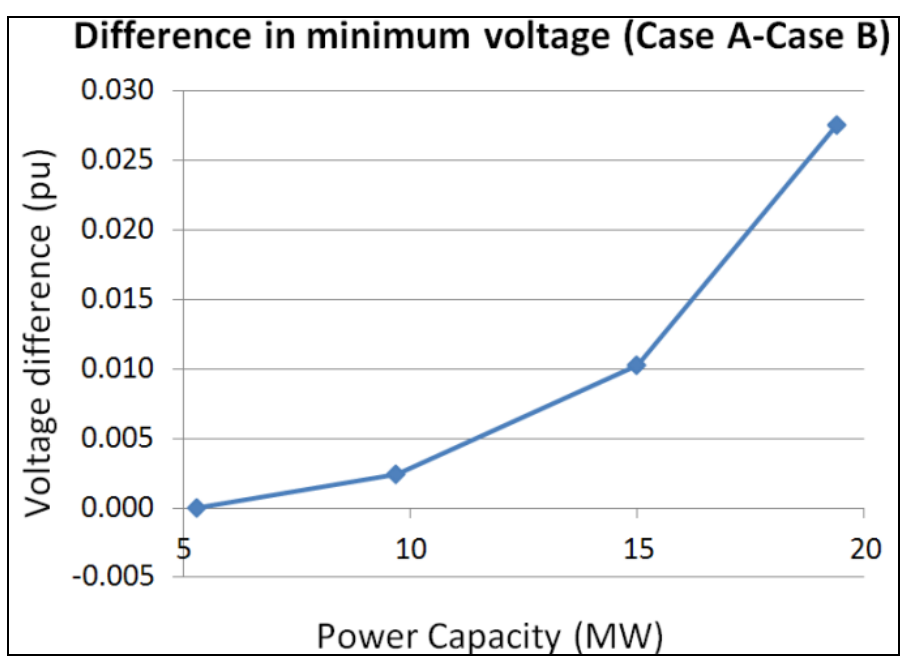

Figure 12 Difference in minimum voltage between Cases $A$ and $B$

In conclusion, based on the above mentioned assumptions, the considered wave farm is grid compliant up to $20 \mathrm{MW}$ included, with respect to voltage limit requirements. Maximum voltage variations to expect from the studied $20 \mathrm{MW}$ farm would be in the range of $-0.06 \mathrm{pu}$.

\section{3-Flicker}

The main outcome of this flicker study is that this parameter will have to be considered carefully before increasing the farm power capacity above the initially planned $5 \mathrm{MW}$.

Simulations using both the best and the worst scenarios show that flicker level will be close to, and may exceed, the allowed limit (0.35) for a power capacity of $20 \mathrm{MW}$. Figure 13 shows flicker level for Case A and Figure 14 flicker level for Case B.

Both figures show also that, as expected, flicker level increases with the farm power capacity. As mentioned earlier, it is thought that it is not the power capacity as such that has a direct influence on flicker level, but the number of devices included in the farm. Each wave makes a wave converter generate electrical power, which then induces a voltage variation at the PCC. Assuming mono-directional waves propagating along an array of wave converters, the wave farm power output reflects the voltage variations caused by each of its devices generating power peaks at different time instants.

Hence, the number of voltage variations induced by a single wave over a given period is effectively increased when the number of devices included in the farm is increased.
As these variations remain within a range of relatively low frequency (much below $8.8 \mathrm{~Hz}$, which is the peak of flicker perceptibility), increasing the number of variations for a given period is then equivalent to increasing the flicker perceptibility of the customer to these variations.

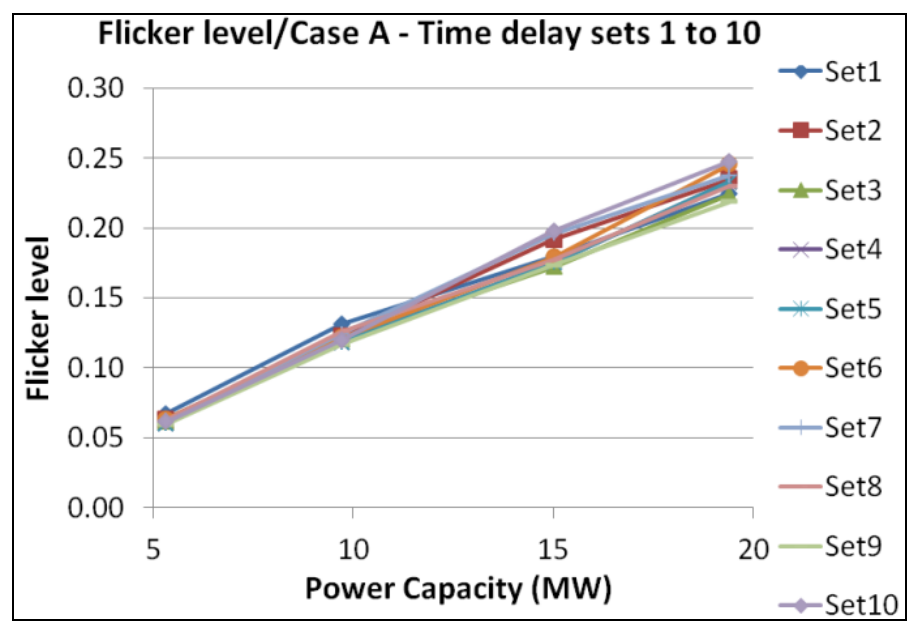

Figure 13 Flicker level versus power capacity (Case A)

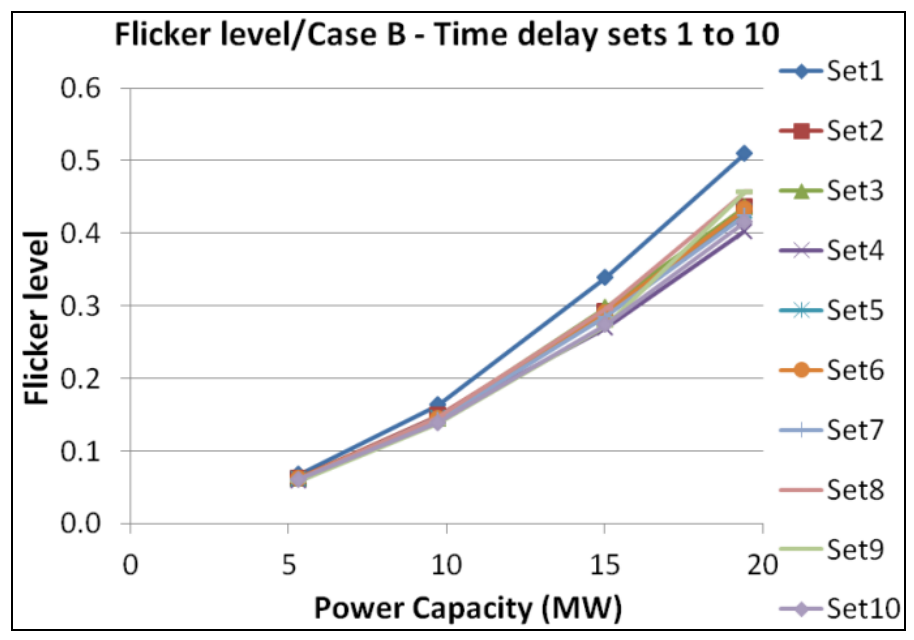

Figure 14 Flicker level versus power capacity (Case B)

However, Figure 15 and Figure 16 show that aggregation with non-zero time delay shifts between generators can be beneficial also: a worst case scenario (time delay set 11) would lead to a flicker level of up to 0.72. On the contrary, in scenarios for which non-zero time delays are used, maximum flicker level for a wave farm of $20 \mathrm{MW}$ is maintained under 0.247 (Case A) or 0.509 (Case B). Hence, although an increasing number of devices makes the flicker level increase, time delays between the generator outputs (hence the aggregation effect) also helps reducing this level. 


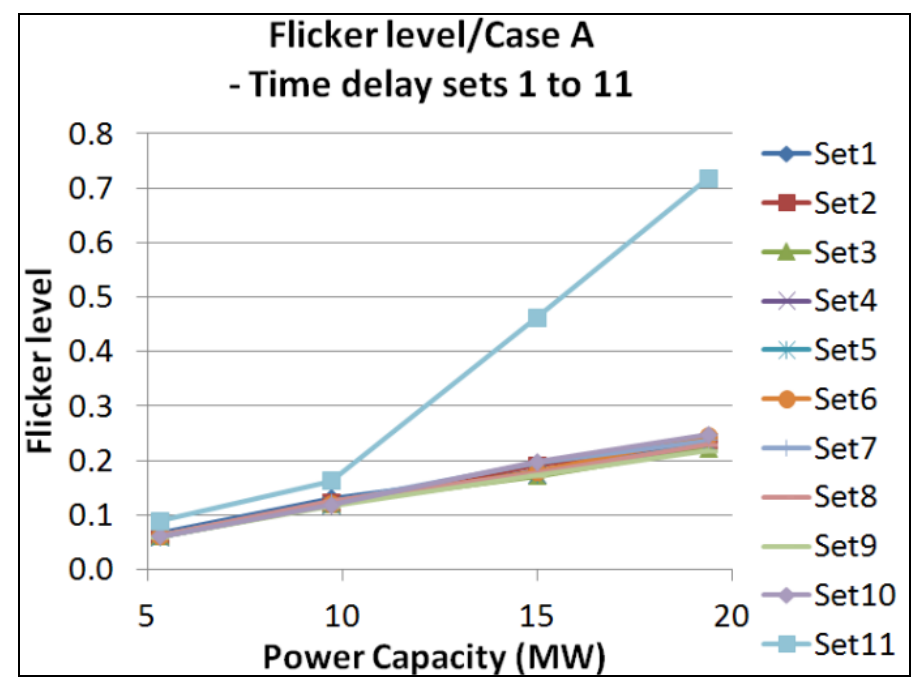

Figure 15 Flicker level (Case A, including worst case Set 11)

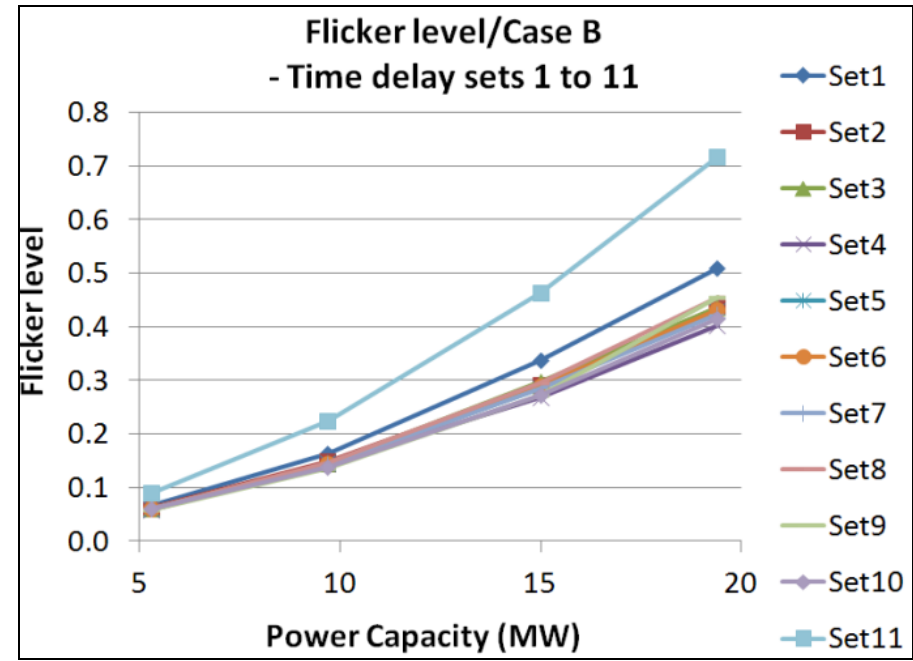

Figure 16 Flicker level (Case B, including worst case Set 11)

In order to quantify the benefits of aggregation on flicker level, the sensibility of this criterion to the randomly-selected time delay sets was analysed. Sensibility for a given case (A or B) was calculated as follows:

$$
S=\frac{\max \left(P s t_{i}\right)-P s t_{i}}{\max \left(P s t_{i}\right)}
$$

Where Pst $_{\mathrm{i}}$ is the maximum flicker level of an individual time delay set (as two values are available for each set), and $\max \left(\mathrm{Pst}_{\mathrm{i}}\right)$ is the maximum flicker level over time delays 1 to 10 (worst case Set 11 excluded)

Figure 17 shows the maximum flicker level sensibility with respect to time delay sets for each power capacity, which can be as high as $16 \%$ for Case A and $21 \%$ for Case B. Besides, the minimum value for the maximum sensibility is always above $12 \%$. This shows that different aggregation conditions (hence different geometrical configurations) can have a significant impact on power quality from a flicker level perspective.

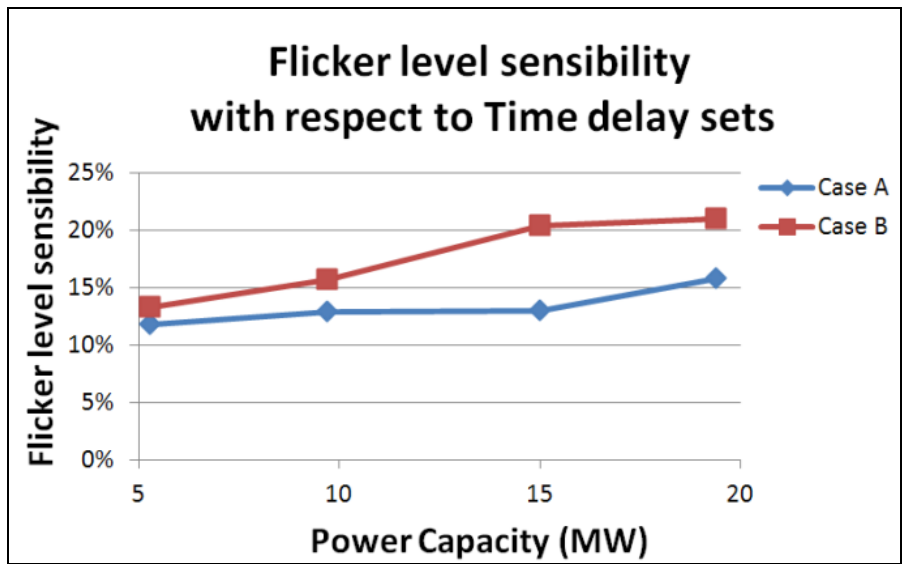

Figure 17 Maximum flicker level sensibility with respect to time delay sets

The figure below shows the maximum flicker level recorded for both cases A and B (over all sets, but excluding worst case set 11). Wave direction with respect to wave farm alignment clearly has an influence on flicker level, as Cases A and B show very different flicker level trends with respect to power capacity.

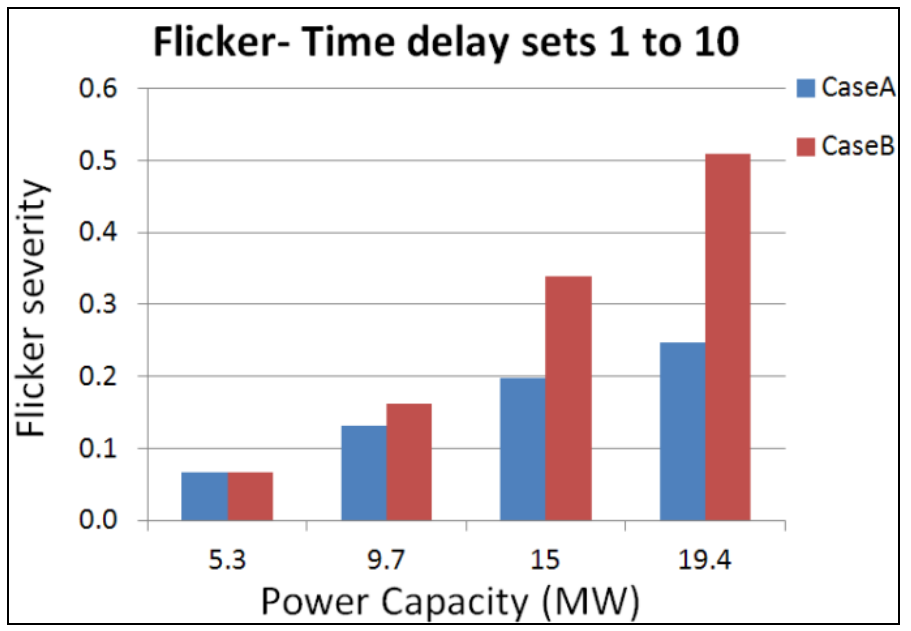

Figure 18 Maximum flicker level (Cases A and B)

Case B shows a much greater flicker level than Case A for a power capacity from $10 \mathrm{MW}$ to $20 \mathrm{MW}$. In Case B, as a higher number of generators produce the same power at the same time, the wave farm power peaks are higher in amplitude than in Case A for which the farm power output is more smoothed. An increase in voltage variation amplitude leads to an increase in the flicker level caused by this variation. Hence, Figure 18 demonstrates that in this case, it is less detrimental, from a flicker level perspective, to increase the number of variations over a given period (Case A) than to increase the variation amplitude (Case B). 
A final interesting point concerns the flicker level variation with respect to power capacity. Although flicker level seems to increase quite rapidly with power capacity in Case B, it has a more moderate trend in Case A. A more detailed analysis of the voltage variation spectrum in the different scenarios would help determining the causes of observed trends.

\section{CONCLUSIONS, DISCUSSION AND FUTURE WORK}

In conclusion, the influence of an increasing power capacity, of different aggregation conditions and of wave direction on maximum/minimum voltage levels has been detailed. The same study has been carried out with respect to maximum flicker level.

The wave farm was demonstrated not to pose any over- or under-voltage issue over the full range of power capacity values studied in the article. Flicker level, however, should be considered with great attention from a power capacity above $10 \mathrm{MW}$. In future work, additional time series generated in different wave climates will be used in power system simulations. In addition, a novel dynamic model for wave energy converters will be used. This model, converting wave elevation time series into electrical power, will make possible the modelling of device aggregation based on wave propagation. Finally, power factor control will be optimised to allow voltage control at the PCC.

Regarding the study on flicker level, this article does not state in a general manner that flicker level increases continuously with the number of wave devices in a farm. With a sufficient number of devices, greater than the one studied here (22 generators), the smoothing effect on the wave farm power fluctuations may be increased and consequently might not lead to any further increase in the flicker level.
In a sufficiently large wave farm, it is assumed that flicker level may also decrease as a function of the number of units. Introducing storage means may decrease dramatically the number of generators necessary to maintain, or even decrease, flicker level.

\section{ACKNOWLEDGMENTS}

The authors wish to acknowledge the Science Foundation Ireland funding agency (Charles Parsons Initiative). They also wish to thank Florent Thiebaut and James Kelly, Ocean Energy Research Engineers at HMRC for their technical help.

\section{REFERENCES}

[1] EirGrid "Transmission Forecast Statement", accessed in December 2011.

[2] "Testing of a floating OWC device with movable guide vane impulse turbine power take-off', F. Thiebaut, D.O'Sullivan, P. Kracht, S. Ceballos, J. López, C. Boake, J. Bard, N. Brinquete, J. Varandas, L.M.C. Gato, R. Alcorn, A.W. Lewis, Proceedings of the $9^{\text {th }}$ European Wave and Tidal Energy Conference, 2011

[3] "Ocean Waves and Oscillating Systems, Cambridge University Press", J. Falnes, 2002

[4] ESB Distribution Code, version 2.0, October 2007

[5] "Optimisation du dimensionnement d'une chaîne de conversion électrique directe incluant un système de lissage de production par supercondensateurs. Application au houlogénérateur SEAREV", J. Aubry, PhD thesis, November 2011

[6] "Power quality assessment from the LIMPET wave-power station", R. Alcorn, W.C. Beattie, Proceedings of the International Society of Offshore and Polar Engineers, 2001 